is calculated. After a little practice, the complete operation can be carried out in an hour and a half, so that in this respect alone the method is greatly to be preferred.

When duplicate determinations are desired only one fusion is necessary, for two separate oxidations may be taken from the total $25^{\circ} \mathrm{cc}$. In the data which are given in the last column of Table $\mathrm{I}$ each figure represents a separate fusion and oxidation, and in the sixteen determinations, representing duplicate fusions on eight different soils, the maximum difference between duplicates amount to only 0.002 per cent. No determinations were discarded in compiling this table.

\begin{tabular}{|c|c|c|c|c|c|c|c|}
\hline \multirow{2}{*}{$\begin{array}{l}\text { Exp. } \\
\text { No. }\end{array}$} & \multirow{2}{*}{$\begin{array}{l}\text { Soil } \\
\text { No. }\end{array}$} & \multicolumn{4}{|c|}{ Walters' method, MnO in extractions } & \multirow{2}{*}{$\begin{array}{l}\text { I-IV. } \\
\text { Total. }\end{array}$} & \multirow{2}{*}{$\begin{array}{l}\text { Authors } \\
\text { method. }\end{array}$} \\
\hline & & I. & II. & III. & IV. & & \\
\hline 1 & 3490 & 0.082 & 0.020 & 0.004 & trace & 0.106 & 0.109 \\
\hline 2 & 3490 & 0.080 & 0.027 & 0.005 & $?$ & 0.112 & 0.111 \\
\hline 3 & 3490 & 0.060 & 0.042 & trace & ? & 0.102 & \\
\hline 4 & 3490 & 0.095 & 0.013 & trace & $?$ & 0.108 & \\
\hline 5 & 3490 & 0.095 & 0.013 & trace & $?$ & 0.108 & \\
\hline 6 & 3490 & 0.064 & $0.016\}$ & not & & & \\
\hline 7 & 3490 & 0.046 & $0.029\}$ & determined & & & \\
\hline 8 & 3486 & 0.045 & & sot determined & & & 0.107 \\
\hline 9 & 3486 & 0.052 & & & & & 0.105 \\
\hline 10 & 3487 & 0.018 & & & · & & 0.111 \\
\hline 11 & 3487 & 0.028 & & & & & 0.110 \\
\hline 12 & 3488 & 0.020 & & & & & 0.111 \\
\hline 13 & 3488 & & & & & & 0.112 \\
\hline 14 & 3489 & 0.025 & & & & & 0.120 \\
\hline 15 & 3489 & 0.031 & & & & & 0.119 \\
\hline 16 & 3491 & 0.044 & & & & & 0.123 \\
\hline 17 & 3491 & 0.044 & & & & & 0.125 \\
\hline 18 & 3483 & 0.060 & & & & & 0.096 \\
\hline 19 & 3483 & 0.060 & & & & & 0.098 \\
\hline 20 & 3459 & 0.033 & & & & & 0.067 \\
\hline 2.1 & 3459 & & & & & & 0.067 \\
\hline
\end{tabular}

I. We have found that Walters' method for the determination of small quantities of manganese, as described by Washington and Hillebrand, is not applicable to Nebrasks soils, but that in some instances four extractions on a one-gram sample with hydrofluoric and sulfuric acids were necessary before all of the manganese was obtained in solution.

2. We have found that when such soils are fused with sodium carbonate and the solution of this melt is acidified with sulfuric acid and oxidized by means of sodium bismuthate, that all of the manganese is oxidized to permanganic acid, and may easily be estimated colorimetrically.

3. We claim for this method greater rapidity, absence from irritating fumes, less danger of loss by spattering, more ease of operation in unexperienced hands, duplicate determinations on one sample of soil, and much greater accuracy.

\section{ALTERING THE COMPOSITION OF INDIAN CORN BY SEED SELECTION. ${ }^{1}$}

By L. H. SMITH.

Received January 8, 1912

In a paper presented before the American Chemical Society in 1899 Dr. C. G. Hopkins reported a line of experiments undertaken at the Illinois Experiment Station to influence the composition of the corn

\footnotetext{
1 Presented at A. C. S. Meeting at Washington, D. C., December, 1911
}

kernel by selection and breeding. At that time the experiments had been under way only about two years, but already results had been obtained sufficiently pronounced to indicate the possibility of changing the composition of the corn kernel as regards protein, oil and carbohydrates. In fact, in his conclusion the author remarks that "while it may require ten or twenty years' work to enable one to form a very definite opinion as to the extent to which it possible to influence the chemical composition of corn, it is believed that the data thus far obtained may be of practical and scientific value."

Since the time this statement was made this investigation has been continued and twelve years' work has been added to these experiments. No further report, however, has been given to this Society, and in view of this fact it was thought that the members would be interested to learn regarding the present status of the work.

Inasmuch as the general purpose of the investigation and the methods of carrying it out have been given already quite fully in the above-mentioned paper and elsewhere (see Bull. I28, Illinois Agricultural Experiment Station), it will be the present plan to mention only as much of this matter as is necessary to an intelligent understanding of the results, the chief purpose being to give a brief résumé of the results up-to-date.

Stated briefly, the proposition involved in this investigation was to take a variety of corn and through selection and breeding try to influence the composition of the grain in four different directions, namely: I, Increase the protein content; 2 , Decrease the protein content; 3 , Increase the oil content; 4 , Decrease the oil content.

Through a preliminary study involving the analyses of a good many samples of different ears and parts of ears the principles of the selection were established. It was found that there is considerable variation among different ears with respect to composition, while the kernels within a single ear are comparatively uniform; that is to say, the ear can be taken as the unit of selection and this gives the working basis. Thus the method is to take two or three rows of kernels lengthwise of the ear as a sample for analysis. If the ear proves to be suitable for seed the remaining kernels are planted.

Starting in 1896 with a variety then known as Burr's White, ${ }^{6} 6_{3}$ ears were chosen and analyzed, determinations being made for protein, oil, ash and carbohydrates. According to the percentage of the constituents, four lots of these ears were picked out with which to start the four respective breeding plots, a high protein plot, a low protein plot, a high oil plot, and a low oil plot. Each ear was planted in a separate row, the different plots being isolated in order to avoid contamination from cross pollination. From the harvest a large number of ears were analyzed from each plot, and based upon these results ears were selected for seed with which to plant the respective plots the following year.

This general plan, with a few minor changes of 
detail, has been followed year after year until we now have the results for I4 generations (the samples for the fifteenth generation have not yet been analyzed). In this manner four different strains emanating from the same variety have been derived. It has been extremely interesting to watch their gradual evolution. This may be shown in outline by the following tabular arrangement:

4.

Breeding for High ANd Low Protein.

Average per cent. protein in crop each generation.

$\begin{array}{cccc}\text { Year. } & \text { High protein. } & \text { Low protein. } & \text { Difference. } \\ 1896 & 10.92 & 10.92 & 0.00 \\ 1897 & 11.10 & 10.55 & 0.55 \\ 1898 & 11.05 & 10.55 & 0.50 \\ 1899 & 11.46 & 9.86 & 1.60 \\ 1900 & 12.32 & 9.34 & 2.98 \\ 1901 & 14.12 & 10.04 & 4.08 \\ 1902 & 12.34 & 8.22 & 4.12 \\ 1903 & 13.04 & 8.62 & 4.42 \\ 1904 & 15.03 & 9.27 & 5.76 \\ 1905 & 14.72 & 8.57 & 6.15 \\ 1906 & 14.26 & 8.64 & 5.62 \\ 1907 & 13.89 & 7.32 & 6.57 \\ 1908 & 13.94 & 8.96 & 4.98 \\ 1909 & 13.41 & 7.65 & 5.76 \\ 1910 & 14.87 & 8.25 & 6.62\end{array}$

BREEDING FOR HIGH AND LOW OIL. Average per cent, oil in crop each generation.

$\begin{array}{rrrc}\text { Year. } & \text { High oil. } & \text { Low oil. } & \text { Difference. } \\ 1896 & 4.70 & 4.70 & 0.00 \\ 1897 & 4.73 & 4.06 & 0.67 \\ 1898 & 5.15 & 3.99 & 1.16 \\ 1899 & 5.64 & 3.82 & 1.82 \\ 1900 & 6.12 & 3.57 & 2.55 \\ 1901 & 6.09 & 3.43 & 2.66 \\ 1902 & 6.41 & 3.02 & 3.39 \\ 1903 & 6.50 & 2.97 & 3.53 \\ 1904 & 6.97 & 2.89 & 4.08 \\ 1905 & 7.29 & 2.58 & 4.71 \\ 1906 & 7.37 & 2.66 & 4.71 \\ 1907 & 7.43 & 2.59 & 4.84 \\ 1908 & 7.19 & 2.39 & 4.80 \\ 1909 & 7.05 & 2.35 & 4.70 \\ 1910 & 7.72 & 2.11 & 5.61\end{array}$

In considering these data attention should be called to the fact that environmental conditions exert an influence upon the protein as well as the oil content and a study of these results reveals some pronounced seasonal effects. By having a "high" and a "low" plot of each, however, we obtain a check which enables us to eliminate these seasonal effects to some extent. Thus the last column of the table showing the difference in per cent. each year furnishes the best information of the real progress due to heredity.

Without going further into a detailed discussion of the figures we may say by way of summary that starting with a variety of corn of average composition it has been possible by 14 years of breeding to increase the protein content from 10.92 per cent. in the original, to 14.87 per cent. in the crop of I9Io, at the same time by selection in the opposite direction, to decrease this constituent to 8.25 per cent. Even more striking changes than these have been produced in the oil content. The oil has been increased from 4.70 per cent. in the original to 7.72 per cent in the crop of I9I0 while at the same time in another strain it has been decreased to 2,r I per cent.

In other words, out of a single variety of corn two strains have been developed of which one is now nearly twice as rich in protein as the other, and two other strains have been developed, the one of which is now more than three times as rich in oil as the other.

The question arises as to the effect of this selection upon the composition of parts of the plant outside of the kernel. This matter has been studied by analyzing each year different plant parts in the various strains. Without entering into any discussion of the results it may be stated in a general way that as yet we have been able to find no pronounced changes in the composition of other parts of the plant resulting from the changes produced in the grain.

Another practical question always arises in this connection, and that is regarding the effect of this selection upon productive qualities. It may be said that in spite of the rigorous selection for special characters to which this corn has been subjected, the yields in these four strains have, in general, been quite well maintained. Selection for high protein seems to have been accompanied in this instance by a somewhat diminished yield as measured by bushels of corn per acre. If, however, we place it upon the basis of pounds of protein per acre our high protein strain is sufficiently higher in percentage, so that it yields more protein per acre than the ordinary varieties growing alongside it in the productivity tests.

College of Agriculture,

\section{RELATION OF ACTIVE POTASH TO POT EXPERIMENTS. ${ }^{1}$} By G. S. FrAPS.

Received March 25, 1912.

By the term "active potash" we mean that soluble in $N / 5$ nitric acid. This solvent has been in use for some time for extracting the more soluble potash and phosphoric acid from the soil. As pointed out in a previous article, the quantity of phosphoric acid extracted is related to the results of pot experiments on the soil. Similar experiments will here be reported on potash.

Pot experiments with representative Texas soils have been made at this station for seven years. The experiments have been carried on under diverse conditions, sometimes not favorable to the best growth of the plants. The plants were grown in Wagner pots containing 500 grams soil, applications of fertilizer being made to the various pots. The pots were kept in houses covered partly or completely with canvas, in order to moderate the temperature. A crop is regarded as very deficient if it is only 50 per cent. or less, of the completely fertilized crop. If less than $9 \circ$ per cent., it is considered deficient (D). If between $9 \circ$ and I $_{0}$ per cent., it is considered as not deficient (S). If over r Io per cent., it is considered that the fertilizer injures the crop ( $\mathrm{T})$. The crop without potash (PN) is always compared with the crop with potash (PNK).

Relation of Deficiency to Active Potash,-The I72 soils studied have been divided into groups according to their content of active potash. The following

1 A full account of this work will be published as Bulletin 145 of the Texas Experiment Station. 